\title{
Exploring community health worker roles, support, and experiences in the context of the COVID-19 pandemic in Bangladesh
}

Frontline Health Project

Follow this and additional works at: https://knowledgecommons.popcouncil.org/departments_sbsr-rh How does access to this work benefit you? Let us know!

\section{Recommended Citation}

Frontline Health Project. 2021. "Exploring community health worker roles, support, and experiences in the context of the COVID-19 pandemic in Bangladesh," Frontline Health Results Brief. Washington, DC:

Population Council. 


\section{EXPLORING COMMUNITY HEALTH WORKER ROLES, SUPPORT, AND EXPERIENCES IN THE CONTEXT OF THE COVID-19 PANDEMIC IN BANGLADESH}

\section{BACKGROUND}

Community health workers (CHWs) are critical actors within community health systems, providing a range of reproductive, maternal, child, and primary health care information, counseling, and services. As community members, $\mathrm{CHWs}$ understand the local context and link their communities to care [1]. In pandemics like COVID-19, they continue to provide routine services in addition to undertaking increased responsibilities. While $\mathrm{CHWs}$ are innovative in their strategies to sustain their work, they operate under challenging circumstances including limited guidance and support and potential hostility from communities and/or facility-based providers.

Bangladesh's CHWs - specifically, government-employed cadres known locally as Family Welfare Assistants (FWAs) and Health Assistants (HAs) - continue to work during COVID-19. Typically, both FWAs and HAs provide a range of counseling and services on family planning and general health, respectively $[3,4]$. In addition to providing health information and counseling at the household level, FWAs and HAs work closely with primary health care centers at upazila and union levels.

COVID-19 was first detected in Bangladesh on 8 March 2020, and there were 772,187 confirmed cases and 11,878 confirmed deaths in the country as of 8 May 2021 [2]. At the onset of the pandemic, with technical guidance from the Ministry of Health and Family Welfare (MoHFW), the government initiated strategies to prevent the spread of COVID-19. These included district/area lock downs and periodic country-wide lock downs, enforcing mask-wearing and social distancing in public, promoting safe hygiene practices, enforcing isolation/ quarantine for suspected/confirmed cases, facilitating institutional treatment, and facilitating community-based prevention practices by engaging $\mathrm{CHWs}$ to respond to COVID-19 in their communities [5].

The government initiated vaccine provision for all adults over 40 years of age in February 2021. While there is currently no engagement on vaccines at the community level, $\mathrm{CHWs}$ help create awareness.

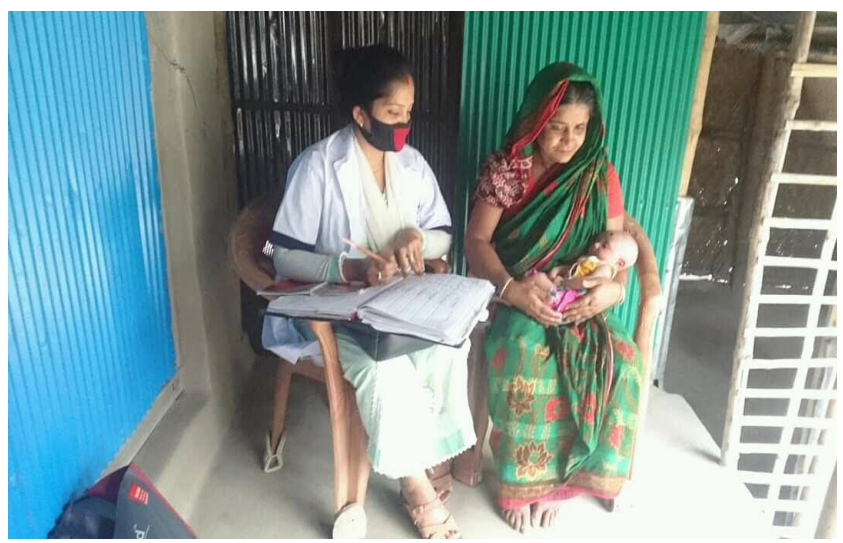

This brief presents results from the Frontline Health project's study in Bangladesh which explores CHWs' perspectives on educating communities, providing care, and health reporting during the pandemic.

\section{KEY FINDINGS}

1. In Bangladesh, CHWs continue carrying out their routine work at slightly decreased levels during COVID-19 compared to the beginning of the pandemic.

2. CHWs are educating households and connecting clients to advanced care for COVID-19; however, they are receiving less supportive supervision during the pandemic.

3. CHWs face instrumental and health/safety challenges while working, including a lack of adequate masks, hand sanitizer/soap, and gloves; barriers to travel; and inconsistent or inadequate training on COVID-19 screening, reporting, and referring.

4. As key providers of health education in their communities, CHWs are in an optimal position to inform their clients about misconceptions surrounding the COVID-19 vaccine and encourage its uptake. 


\section{RESULTS}

Quantitative survey results revealed that $81 \%$ of CHWs in our sample $(n=370)$ are female, $31 \%$ are between 30-40 years old and 35\% are over 50 years old, and $75 \%$ received a higher secondary and above education.
Most $\mathrm{CHWs}$ reported that they had been working over 10 years (85\%), with very few $\mathrm{CHWs}$ reporting less than five years' experience (5\%).

Among $\mathrm{CHWs}$ that reported living in the community in which they work $(n=254)$, the average travel time to the farthest household was 11-20 minutes, followed by 21-30 minutes.

TABLE 1. CHARACTERISTICS OF CHWS ( $\mathbf{N}=\mathbf{3 7 0}$ )

\begin{tabular}{|c|c|c|c|}
\hline Characteristic & $\begin{array}{l}\text { FWA (\%) } \\
{[n=204]}\end{array}$ & $\begin{array}{l}\text { HA (\%) } \\
{[n=166]}\end{array}$ & $\begin{array}{l}\text { Total (\%) } \\
{[\mathrm{N}=370]}\end{array}$ \\
\hline \multicolumn{4}{|l|}{ Gender } \\
\hline Female & 100 & 57 & 81 \\
\hline Male & 0 & 43 & 19 \\
\hline \multicolumn{4}{|l|}{ Age } \\
\hline $1<30$ years & 11 & 2 & 7 \\
\hline 30 - 35 years & 20 & 18 & 19 \\
\hline $36-40$ years & 4 & 21 & 12 \\
\hline $41-45$ years & 5 & 6 & 6 \\
\hline $46-50$ years & 20 & 25 & 22 \\
\hline$>50$ years & 40 & 28 & 35 \\
\hline \multicolumn{4}{|l|}{ Education level } \\
\hline Secondary (Incomplete) & 3 & 0 & 2 \\
\hline Secondary (Complete) & 42 & 1 & 23 \\
\hline Higher secondary and above & 55 & 99 & 75 \\
\hline \multicolumn{4}{|l|}{ Time working as a $\mathrm{CHW}$} \\
\hline$<5$ years & 9 & 1 & 5 \\
\hline $5-10$ years & 13 & 4 & 10 \\
\hline$>10$ years & 78 & 95 & 85 \\
\hline \multicolumn{4}{|l|}{ Received incentives ${ }^{\star}$} \\
\hline Salary & 100 & 100 & 100 \\
\hline Allowances (transport, lunch, airtime) & 80 & 84 & 82 \\
\hline Non-financial (food, backpacks) & 70 & 82 & 75 \\
\hline \multicolumn{4}{|l|}{ Location of CHW's work } \\
\hline Urban informal settlements & 12 & 2 & 7 \\
\hline Peri-urban & 10 & 31 & 20 \\
\hline Rural & 78 & 67 & 73 \\
\hline \multicolumn{4}{|c|}{ Time to reach farthest household among $\mathrm{CHWs}$ that live in community** } \\
\hline 10 minutes or less & 27 & 7 & 20 \\
\hline $11-20$ minutes & 41 & 41 & 41 \\
\hline 21 - 30 minutes & 23 & 34 & 27 \\
\hline$>30$ minutes & 9 & 18 & 12 \\
\hline \multicolumn{4}{|l|}{ Main mode of travel since pandemic } \\
\hline By foot & 23 & 4 & 14 \\
\hline Bicycle & 0 & 2 & 1 \\
\hline Motorbike & 7 & 21 & 13 \\
\hline Bus & 1 & 3 & 2 \\
\hline Taxi/ CNG taxi & 31 & 40 & 35 \\
\hline Easy bike/ rickshaw/ boat & 38 & 30 & 35 \\
\hline
\end{tabular}

*Multiple responses, ${ }^{* *} N=254$ 
CHWs continue to provide routine services in their communities at relatively high levels.

Our data indicate that the majority of $\mathrm{CHWs}$ were able to carry out their routine work during the pandemic, with some disruptions in routine activity at the beginning.

At the onset of the pandemic, almost $12 \%$ of $\mathrm{CHWs} \mathrm{(} n=$ 44) reported that they were not able to carry out their routine work at all and $27 \%$ of $\mathrm{CHWs}$ reported that they were able to carry out their routine work "somewhat" $(n=101)$. Among these CHWs ( $n=145), 77 \%$ reported physical security concerns, followed by lack of transport (70\%), communities' refusal due to fear of infection (69\%), medical safety concerns (65\%), and work shifting to COVID-19 (9\%) as the reasons why they could not continue their work as usual (Figure 1).
Six months into the pandemic, nearly all CHWs were able to carry out their routine work (data not shown).

CHWs are providing services less frequently during the pandemic than they were prior.

The percentage of $\mathrm{CHWs}$ providing routine services decreased slightly during the pandemic, as some shifted their work completely towards COVID-19 or they were unable to carry out their work due to various pandemicrelated challenges as shown in Figure 1. However, prior to the pandemic, $\mathrm{CHWs}$ were providing services at high frequencies close to $100 \%$, and some of the decreases were only slight. For instance, the percentage of CHWs providing counseling and direct primary health care services decreased from $100 \%$ prior to the pandemic to 96\% six months into the pandemic (Figure 2).

\section{FIGURE 1. CHWS' REPORTED REASONS FOR NOT CARRYING OUT ROUTINE TASKS AT ONSET OF PANDEMIC (N =145)}

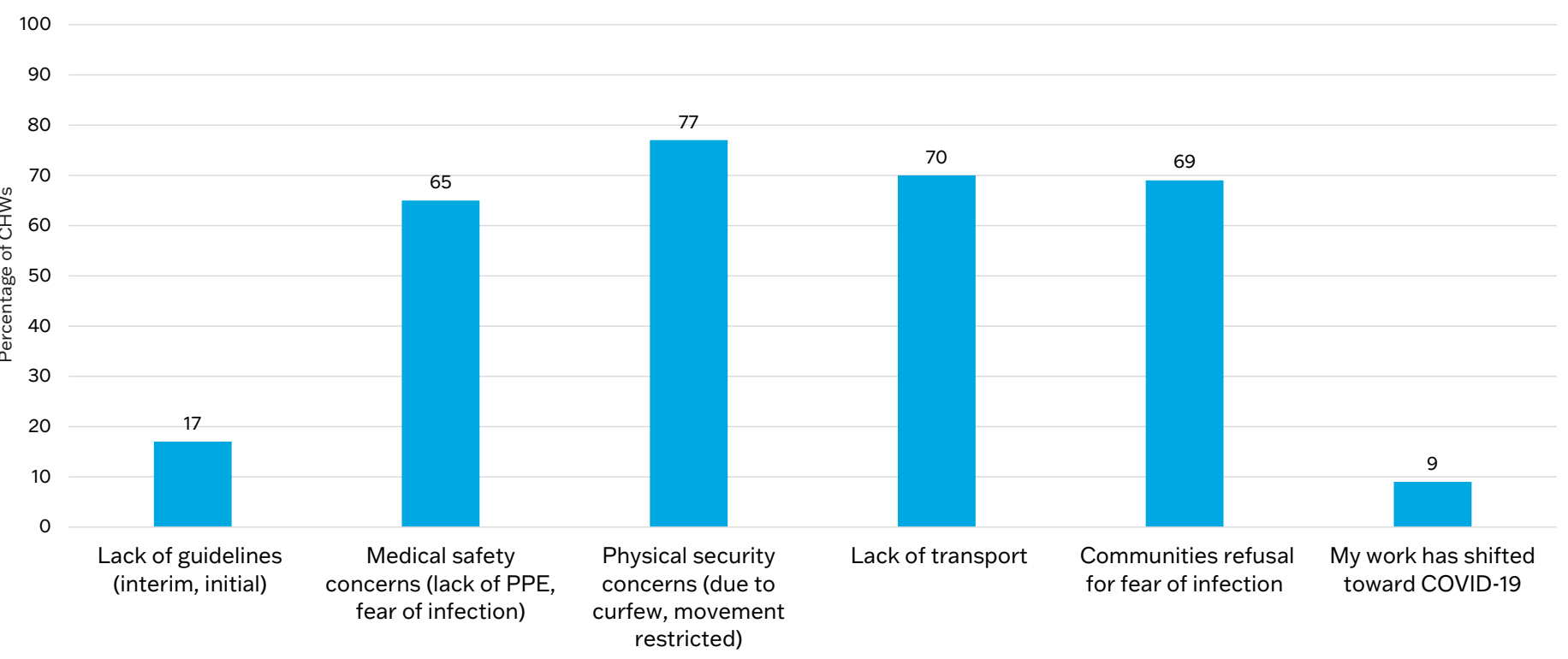

FIGURE 2. CHWS' RESPONSIBILITIES BEFORE AND DURING THE PANDEMIC ( $\mathbf{N}=\mathbf{3 7 0}$ )



- \% CHWs providing service before pandemic $\quad$ \% $\mathrm{CHWs}$ providing service six months into pandemic 
$\mathrm{CHWs}$ also reported slight decreases in home-based care for postnatal women and newborns, mental health counseling, documenting or referring for gender-based violence (GBV), and education on water, sanitation, and hygiene (WASH), among others (data not shown).

\section{CHWs reported decreased in-person supportive supervision during the pandemic.}

Our data show that most $\mathrm{CHWs}$ were supervised through ad-hoc in-person one-on-on meetings or regularly scheduled team meetings with their supervisors prior to the pandemic; however, during the pandemic, the number of CHWs reporting in-person methods of supervision decreased slightly. The percentage of $\mathrm{CHWs}$ reporting supervision through phone calls stayed the same during the pandemic (91\%), while the number of $\mathrm{CHWs}$ reporting that they were supervised through digital communications (WhatsApp) increased from 18\% to $33 \%$ (data not shown). Overall, CHWs are receiving less frequent direct supervision and support than they were prior to the pandemic, with the exception of digital communications.

CHWs reported engaging in various activities in their communities related to prevention, treatment, referring, and reporting COVID-19.

Eighty percent of CHWs in our sample $(n=296)$ reported that they received any training or guidance on COVID19-related services, with variable training on specific aspects related to contract tracing and continuing of community-based services (Table 2). Of the CHWs who reported receiving training, $64 \%$ reported those training messages were "very clear" (data not shown).

Ninety-nine percent of CHWs reported educating community members about COVID-19 prevention or treatment (Table 3). Almost all CHWs reported giving specific advice to their communities on prevention and treatment such as wearing masks, frequent hand washing/sanitizing, and social distancing, and the majority gave advice on what to do if exposed or symptomatic (Figure 3).

Almost $100 \%$ of $\mathrm{CHWs}$ reported educating their communities about how to take care of someone with COVID-19 in the home, $69 \%$ reported referring suspected COVID-19 cases for testing, and $61 \%$ indicated they report suspected or confirmed cases. Fewer reported contract tracing for community members who may have COVID-19 (35\%) and reporting suspected cases for advanced care (33\%) (Table 3).

TABLE 2. CHW TRAINING/GUIDANCE ON COVID-19 ( $\mathbf{N}=296)$

\begin{tabular}{|l|c|}
\hline $\begin{array}{l}\text { Percentage of CHWs reporting training or guidance } \\
\text { on specific topic }\end{array}$ & 100 \\
\hline General information about COVID-19 & 100 \\
\hline $\begin{array}{l}\text { Preventive strategies (hand washing practices, social } \\
\text { distance, self-quarantine, etc.) }\end{array}$ & 98 \\
\hline Correct use of PPE (masks, gloves, apron, etc.) & 99 \\
\hline Signs and symptoms of COVID-19 & 57 \\
\hline Contact tracing and community surveillance & 85 \\
\hline Home based care of COVID-19 cases & 73 \\
\hline Continuity of community-based services &
\end{tabular}

TABLE 3. CHW COVID-19 ACTIVITIES ( $\mathbf{N}=\mathbf{3 7 0}$ ) Percentage of CHWs engaged in COVID-19 activity \%

\begin{tabular}{|l|c|}
\hline $\begin{array}{l}\text { Educating community members about COVID-19 } \\
\text { prevention or treatment }\end{array}$ & 99 \\
\hline $\begin{array}{l}\text { Educating communities/households about how to } \\
\text { take care of someone with COVID-19 in the home }\end{array}$ & 100 \\
\hline Referring suspected COVID-19 cases for testing & 69 \\
\hline Reporting suspected or confirmed cases of COVID-19 & 61 \\
\hline $\begin{array}{l}\text { Doing contract tracing for those who may have } \\
\text { COVID-19 in the community you serve }\end{array}$ & 35 \\
\hline $\begin{array}{l}\text { Referring suspected COVID-19 cases for advanced } \\
\text { care at facilities }\end{array}$ & 34 \\
\hline
\end{tabular}

\section{FIGURE 3. PERCENTAGE OF CHWS GIVING SPECIFIC ADVICE ON PREVENTION AND TREATMENT (N=367)}

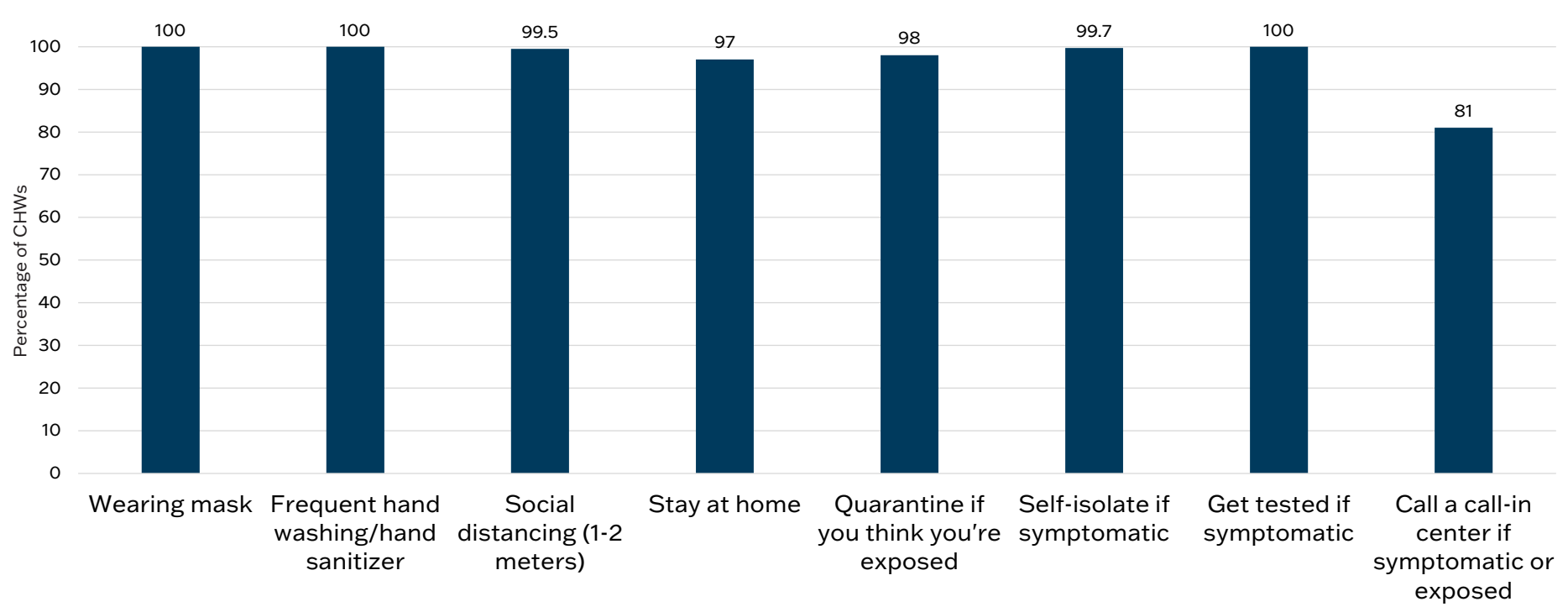




\section{CHWs experienced various COVID-19-related challenges.}

$\mathrm{CHWs}$ reported facing challenges when carrying out their routine work during the pandemic, including barriers to travel, inadequate PPE to feel safe, and $\mathrm{CHW}$ and community fears of contracting COVID-19. Very few CHWs reported shortages of contraception, drugs, or other commodities; $99.5 \%$ of $\mathrm{CHWs}$ reported that they had no challenges with shortages of contraception (Table 4).

One-quarter of CHWs ( $n=92)$ also reported experiencing hostility or mistreatment by the community due to their work. The most common types of $\mathrm{CHW}$ mistreatment were having their advice ignored by clients (54\%), being refused entrance into a client's home (90\%), and being yelled at or spoken to rudely in the community (34\%) (data not shown).

Our data indicate that very few $\mathrm{CHWs}$ received infection prevention supplies regularly in their work, with just $4 \%$ of $\mathrm{CHWs}$ reporting regular provision of masks, gloves, and hand sanitizer. Most $\mathrm{CHWs}$ reported receiving these supplies "irregularly" (data not shown).

\section{CONCLUSION AND NEXT STEPS}

CHWs are a critical source of education and care for their communities during the COVID-19 pandemic, providing routine services in addition to new responsibilities. CHWs are engaged in a range of COVID-19 related activities including educating households on prevention and treatment, contract tracing in their communities, and referring clients to facilities for testing and advanced care. Our data reveal that $\mathrm{CHWs}$ are receiving less in-person supervision during the pandemic; however, levels of supportive supervision overall remain high.

$\mathrm{CHWs}$ reported various challenges such as irregular provision of supplies (masks, gloves and hand sanitizer), lack of transportation, some fear from communities, and their own fears of contracting and/or spreading COVID-19.

To alleviate challenges and provide greater support to $\mathrm{CHWs}$ during the pandemic, we recommend policy and program stakeholders:

1. Invest in digital supportive supervision between $\mathrm{CHWs}$ and their supervisors to foster regular communication.

2. Provide CHWs with masks, gloves, and hand sanitizer/ soap regularly and adequately to alleviate their own and the community's fears of contracting COVID-19.
3. Explore hostility felt by $\mathrm{CHWs}$ in future qualitative work.

4. Employ different channels of educating communities (CHWs, media, virtual messaging) on misinformation and misconceptions around COVID-19 and what they can do to protect themselves from contracting the virus.

5. Systematize CHW's engagement with the vaccine by building their capacity (i.e. providing training) to educate communities on the vaccine and encourage its uptake.

\section{TABLE 4. CHW CHALLENGES ( $\mathbf{N}=370)$}

\begin{tabular}{|l|c|}
\hline Percentage of CHWs reporting challenge & $\%$ \\
\hline Cannot travel because of social distancing regulations & 34 \\
\hline Do not have adequate PPE to feel safe & 60 \\
\hline People fear CHW might spread COVID-19 & 66 \\
\hline CHW fears they may get COVID-19 & 84 \\
\hline Had shortage of contraceptives & 1 \\
\hline Had shortage of drugs & 2 \\
\hline Had shortage of other commodities & 0.5 \\
\hline Public transportation unavailable & 40 \\
\hline
\end{tabular}

\section{CONTACT:}

Sharif Hossain
Population Council
Bangladesh
sharifhossain@popcouncil.org
Pooja Sripad
Population Council
Washington, D.C.
psripad@popcouncil.org

Shongkour Roy

Population Council

Bangladesh

sroy@popcouncil.org

Sarah Kennedy

Population Council,

Washington, D.C.

skennedy@popcouncil.org

\section{REFERENCES}

1. Agarwal S, Kirk K, Sripad P, Bellows B, Abuya T, CE Warren. (2019)Setting the global research agenda for community health systems: literature and consultative review. Hum Resour Health 17, 22. https://doi.org/10.1186/ s12960-019-0362-8

2. Bangladesh WHO COVID profile: https://covid19.who.int/region/searo/ country/bd

3. Frontline Health Project. 2021. Using evidence to advocate for the professional growth of community health workers in Bangladesh. Washington, D.C.: Population Council.

4. Hossain S, Sripad P, Zieman B, Roy S, Kennedy S, Hossain I, Bellows B. Measuring quality of care at the community level using the contraceptive method information index plus and client reported experience metrics in Bangladesh. J Glob Health 2021;11:07007.

5. MoHFW, Health service division. 2020. Bangladesh Preparedness and Response Plan for COVID. http://www.mohfw.gov.bd/index. php?option=com_docman\&task=doc_download\&gid=23359\&lang=en

Suggested citation: Frontline Health Project. 2021. Exploring community health worker roles, supports, and experiences in the context of the COVID-19 pandemic in Bangladesh. Washington, D.C.: Population Council. 